\title{
Mixing Length Approach to Dispersion Through Saturated Porous Media and its Relation to Grain Sizes
}

\author{
飽和多孔体中の分散現象への混合距離的アプローチと粒径の影響
}

\section{Laxmi Prasad DEVKOTA* • Uichiro MATSUBAYASHI* • Fusetsu TAKAGI*

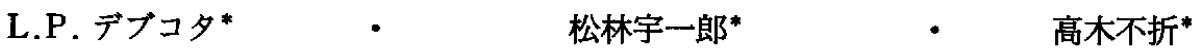

\section{Department of Geotechnical and Environmental Engineering}

\author{
(名古屋大学大学院工学研究科)
}

In this study, dispersion phenomenon inside the saturated porous medium have been discussed applying mixing length theory concept, which is usually used for the turbulent mixing of the particles in surface water regimes. According to this theory, dispersion coefficient can be expressed as a product of the mixing length and the standard deviation of the pore water velocities. It is shown that the dispersion mechanism is different in saturated and unsaturated flow because the change in saturated flow velocity is attributed to the change in hydraulic gradient while the unsaturated flow velocity changes due to the different degrees of saturation of the porous medium.

To check the model for dispersion coefficient and see the characteristics of mixing lengths with respect to grain sizes of the medium, miscible displacement experiments under saturated conditions were carried out using three different sizes uniform glass beads as porous media. Coefficient of variation at saturation, a parameter in saturated dispersion coefficient model, was determined from soil characteristics curves, i.e., suction-moisture content and hydraulic conductivity-moisture content relationships.

Mixing lengths for a particular medium were found almost constant which assumed a value of 1.8 times the grain diameter of the medium. The applicability of the model for the dispersion coefficient, for saturated condition, based on mixing length theory concept was checked by experimental data.

Key words: Dispersion coefficient, Glass beads medium, Mixing length theory, Saturated experiments

本研究は, 通常閒水路や管路流れにおいて乱流にともなう溶質の混合に対して用いられる混合距離理論を, 飽和多孔体内の分散現 象への適用について議論するものである.この理論では, 分散係数は混合距離と間陵実流速の標準偏差との䅡で表される、これまで の実験から，飽和状態と不飽和状態では，分散機構が異なるのがわかっている，それは，流速が，飽和状態では水理勾配によって変 わるのに対し，不飽和状態では媒体内の水分飽和度によって変わるからである.

一様な粒径のガラスビースを媒体とした飽和流れての濃度変化を測定する実験から，分散係数を表現するモデルの検証と粒径毎 の混合匜離特性の把暒を行った.モデルのパラメータとしての実流速の変動係数は, 水分特性曲線と不飽和透水係数〜水分飽和度の 曲線の二つから求めた。

その結果, 混合距離はいずれの粒径に対してもその1.8倍となった。これにより, 分散保数は媒体の透水特性, 水分特性, 粒径及 び平均実流速から求められた理論值と実験值によく一致することが確かめられた。

\section{I . INTRODUCTION}

The movement of solutes such as soluble salts, fertilizer, heavy metals etc. through soils has attracted the attention of agriculturists, hydrologists and environmentalists. Many ef-

\footnotetext{
"Department of Geotechnical and Environmental Engineering, Nagoya University, Chikusa-ku, Nagoya 464-01, Japan 名古屋大学大学院工学研究科地圈棵境工学専攻 $\overline{\mathbf{T}} 464-01$ 名古屋市千種区不老町
} 
forts have been devoted in the past few decades to understand the mechanisms of solute transport through the saturated porous medium. Dispersion is one of the major phenomenon by which the solutes moving with water tend to spread within the bulk soil solution. Dispersion coefficient is therefore considered as one of the most important parameters in solute transport study through the porous materials.

Dispersion coefficient, includes the effects of both molecular diffusion and mechanical disper. sion. Unless the fluid flux is very low, molecular diffusion is a small fraction of the apparent dispersion coefficient and usually ignored. In such conditions, dispersion coefficient, $D$, is often expressed as:

$$
D=\alpha \bar{\nu}
$$

where, $\alpha$ is the dispersivity $(\mathrm{cm})$ and $\bar{\nu}$ is the mean pore water velocity $(\mathrm{cm} / \mathrm{s})$. Sheidegger (1961), Bear (1972), Freeze and Cherry (1979) have reported that equation (1) could be used as an empirical relation to describe the dispersion coefficient in solute transport study under saturated conditions. The $\alpha$ in equation (1) is considered as a characteristic property of the porous medium (Freeze and Cherry, 1979) and assume a constant value for a particular porous medium. Passioura (1971) used the grain radius as an acceptable approximation for the dispersivity value. Perkins and Johnston (1963), Fried and Combarnous (1971), Bear (1972), and Bear and Verruijt (1987) have summarized the results of various researches and concluded that $\alpha$ takes a value of about 1.8 times the grain diameter of the porous medium.

All of these results are empirically obtained and none of these researchers express the dispersion coefficient theoretically. Matsubayashi et al. (1996) formulated $D-\bar{\nu}$ relationship for the porous medium based on the analogy with the turbulence mixing. The deviation of turbulence velocity from the mean flow velocity is analogous to the deviation of pore water velocity resulting from the randomness of the pores of various sizes and shapes, even the flow itself is laminar. Mixing length theory concept has been, therefore, applied to comprehend the dispersion phenomenon through a porous medium. According to mixing length theory, $D$ can be expressed as:

$$
D=\sigma l
$$

where, $\sigma$ and $l$ are the standard deviation of the pore water velocities and mixing length of the flow paths inside the porous medium respectively. In that study (Matsubayashi et al., 1996), why previous investigators found linear relationship of dispersion coefficient with pore water velocity in the lower range of moisture content have been discussed based on this concept. In addition, they have also found mixing length increasing with the average grain size of uniform glass beads medium in the unsaturated displacement experiments.

The above discussion is mainly about the dispersion phenomenon in unsaturated flow. The first aim of this research is, therefore, to derive a formula for dispersion coefficient for the saturated miscible displacement phenomenon based on the mixing theory. The second aim is to see the effect of grain sizes of the medium on mixing lengths, which is a prerequisite for the general dispersion model based on this theory. Experiments were carried out using three different size of uniform glass beads as porous media for these purposes. $\mathrm{NaCl}$ was used as the conducting solution because it is less adsorptive to the beads and also less reactive to other chemicals.

\section{THEORY}

Porous medium can be considered as an assembly of randomly distributed interconnected pores of various sizes and shapes. The flow in the larger pores is faster than in the smaller pores and is much faster at the center of a pore than near the surface. The actual pore water velocity is therefore distributed over a range of velocities. Due to these variations in velocity and erratic flow patterns, the solutes present in the porous medium tend to spread in 
their course of movement. This spreading phenomenon is usually termed as hydrodynamic dispersion.

The variations of the pore water velocity inside the porous medium is due to the different sizes of the pore channels. These water paths, however, are not separated like in capillary bundle model but they meet within a certain distance. Water particles moving in different channels therefore meeting with each other after traveling different distances. It causes the mixing of solutes dissolved in it. Fig. 1 (a) shows a schematic illustration of pore water velocities $(\nu)$ relative to mean pore water velocity $(\bar{v})$ in a porous medium under saturated condition. If the flow process is observed in a moving coordinate system, i.e., moving down with $\bar{\nu}$, we can see that water particles are moving downwards and upwards depending on their particular velocity and mixing with each other after traveling a certain distance. If the pore water concentration is as shown in Fig. 1(b), the net transfer of the solute, $q_{c}$, will be calculated as:

$$
\begin{aligned}
q_{c}= & \left\{C-(d C / d z)\left(l^{\prime} / 2\right)\right\}\left|\nu^{\prime}\right| \\
& -\left\{C+(d C / d z)\left(l^{\prime} / 2\right)\right\}\left|\nu^{\prime}\right| \\
= & -l^{\prime}\left|\nu^{\prime}\right|(d C / d z) \\
= & -l \sigma(d C / d z) \\
= & -D(d C / d z)
\end{aligned}
$$

where $C$ is the concentration $\left(\mathrm{g} / \mathrm{cm}^{3}\right),|\nu|$ is the

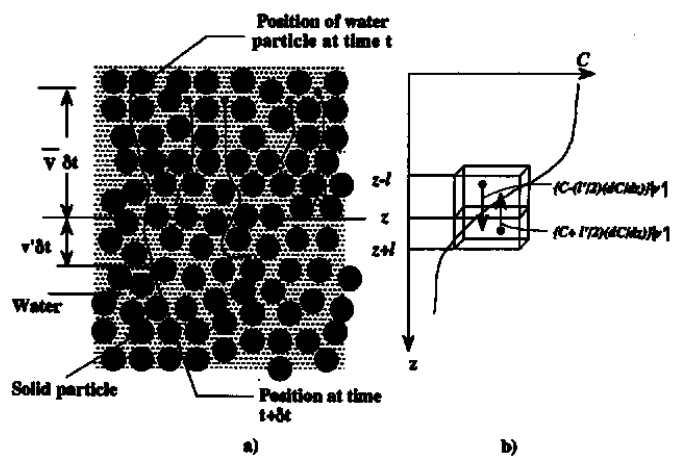

Fig. 1 Schematic diagram of the flow and the concentration of the solute inside the saturated porous medium representative velocity $(\mathrm{cm} / \mathrm{s})$ in both directions, $\sigma$ is the standard deviation of the velocity $(\mathrm{cm} / \mathrm{s})$ used to express $|v|$, both $l^{\prime}$ and $l$ are called mixing lengths $(\mathrm{cm})$ corresponding to the expression of $|v|$ and $\sigma$ respectively and $D$ is the dispersion coefficient. From this equation, equation (2) has been derived. This derivation is based on the analogy of mixing length theory in turbulent flow. Mixing length, $l$, in this sense is a characteristic length of the porous medium within which the'concentration of the solution conform to the surrounding concentration.

The problem here is how to estimate the stan. dard deviation of the pore water velocity, $\sigma$, of equation (2). Matsubayashi et al. (1996) presented the procedure to determine $\sigma$ using suction-moisture content $(\sigma-\theta)$ and hydraulic conductivity-moisture content $(K-\theta)$ relationship. For the convenience of the reader, the procedure is briefly discussed here.

(i) The pore radius, $r$, and the suction head, $\psi$, corresponding to moisture content, $\theta$, can be related as:

$$
r=\frac{2 \gamma}{\rho g \psi}
$$

where $\gamma$ and $\rho$ are surface tension (dyne/cm) and density of water $\left.(\mathrm{g} / \mathrm{cm})^{2}\right)$ respectively and $g$ is the acceleration due to gravity $\left(\mathrm{cm} / \mathrm{s}^{2}\right)$.

(ii) The number of pores, $N$, of size $r$, filled with water for each moisture increment of $d \theta$, in a unit cross sectional area of the porous medium can be determined as:

$$
N=\frac{d \theta}{\pi r^{2}}
$$

(iii) Using Poiseuille's equation for pipe flow, the Darcy flux for a unit hydraulic gradient can be expressed as:

$$
q(\theta)=\frac{1}{\pi} \int_{0}^{\theta} C_{r}(\theta) r^{2} d \theta
$$

where $C_{r}$ is a coefficient. On the other hand, the Darcy flux can be written by Kozeny's relation as:

$$
q(\theta)=K(\theta)=K_{s} S^{\beta}
$$

where $S$ is the degree of saturation. Coefficients $K_{s}$ and $\beta$ can be determined from $K-S$ 
relationship.

(iv) From equations (6) and (7), the coefficient $C_{r}$ in equation (6) can be determined for each $\theta$. For each pipe of size, $r$, the pore water velocity $\nu$ can then be determined as:

$$
\nu=\frac{1}{\pi} C_{r}(\theta) r^{2}
$$

(v) The mean and variance of the pore water velocity at moisture content, $\theta$, can be estimated by equations (9) and (10) respectively.

$$
\begin{aligned}
& \bar{\nu}(\theta)=\frac{1}{\theta} \int_{0}^{\theta} \nu d \theta \\
& \sigma(\theta)^{2}=\frac{1}{\theta} \int_{0}^{\theta}(\nu-\vec{\nu})^{2} d \theta
\end{aligned}
$$

Saturated condition is the limiting case of the unsaturated condition, i.e., when $\theta=\theta_{s}$. The difference between unsaturated case and saturated case is that the change in mean and standard deviation of the pore water velocity are attributed to the different degrees of saturation in the former case while in the later case, they are attributed to their hydraulic gradients. Because the flow in each pore is laminar, pore water velocity in each path linearly relates to the hydraulic gradient. Considering that the values of $\bar{\nu}$ and $\sigma^{2}$ in equations (9) and (10) respectively are evaluated for unit hydraulic gradient, $\bar{\nu}$ and $\sigma$ for a certain hydraulic gradient can be expressed as:

$$
\begin{aligned}
& \bar{\nu}_{(1)}=\bar{\nu}_{(1)} I \\
& \sigma_{(I)}=\sigma_{(1)} I
\end{aligned}
$$

Here, " $I$ " denotes the hydraulic gradient. The terms in brackets represents the respective hydraulic gradient.

The dispersion coefficient for the saturated condition can be given as

$$
\begin{aligned}
& D=l_{(I)} \sigma_{(l)}=l_{(I)} \sigma_{(1)} I_{(I)}=l_{(I)} \frac{\sigma_{(1)}}{\bar{\nu}_{(l)}} \bar{\nu}_{(I)} \\
& \quad=l_{(I)} \lambda \bar{\nu}_{(I)} \\
& \text { where, } \lambda=\frac{\sigma_{(1)}}{\bar{\nu}_{(1)}}
\end{aligned} .
$$

Here, $\lambda$ is the coefficient of variation of pore water velocity at saturation.

It is noted that $l \lambda$ in equation (12) corresponds to the dispersivity, $\alpha$, of equation
(1) . $\lambda$ is a parameter depending solely on a particular porous medium and can be taken as the pore size index for that medium while parameter, $l$, depends on the flow pattern inside the porous medium.

In this model, we need to evaluate the coefficient of variation, $\lambda$ defined in equation (13). $\sigma_{(1)}$ and $\bar{\nu}_{(1)}$ of equation (13) can be calculated by integrating the functions given in equations (10) and (9) respectively upto saturated moisture content, $\theta_{s}$. However, as $\theta \rightarrow \theta_{s}, \psi \rightarrow \psi_{s}(=$ $0)$ and $r \rightarrow \infty$ (equation 4). To avoid this singular point problem, $\psi$ is assumed as $\psi_{a}$ (air entry value) when $\theta=\theta_{s}$ because the change in the amount of moisture content when suction changes from $\psi_{a}$ to $\psi_{s}$ is practically zero. Mix. ing lengths can be determined from the known value of dispersion coefficient (from experiments), $\lambda$ (from $\sigma-\bar{\nu}$ relationship) and average pore water velocity (from experiments).

In this theoretical discussion, it is attempted to make clear the dispersion process and a physically meaningful parameter, the mixing length, has been introduced.

\section{EXPERIMENTS AND ANALYSIS}

\section{Experimental Materials}

Miscible displacement experiments under saturated conditions were carried out in steady state flow conditions. A schematic illustration of the experimental apparatus is shown in Fig. 2. The experimental set up is composed of the experimental column, input supply tanks and an overflow tank. The column was made up of $5 \mathrm{~cm}$ high interconnectable PVC rings having $10 \mathrm{~cm}$ inside diameter. Five of these PVC rings are installed electrodes to monitor the change in specific electrical conductance inside the medium. The electrode was constructed using two cylindrical stainless steel tubes having outside diameter $2.1 \mathrm{~mm}$, and a PVC ring with $10 \mathrm{~cm}$ inside diameter and $5 \mathrm{~cm}$ in height. The two stainless steel tubes were inserted at the middle of the ring, in parallel, keeping them $1.1 \mathrm{~cm}$ apart. Marriotte tanks were used as supply 


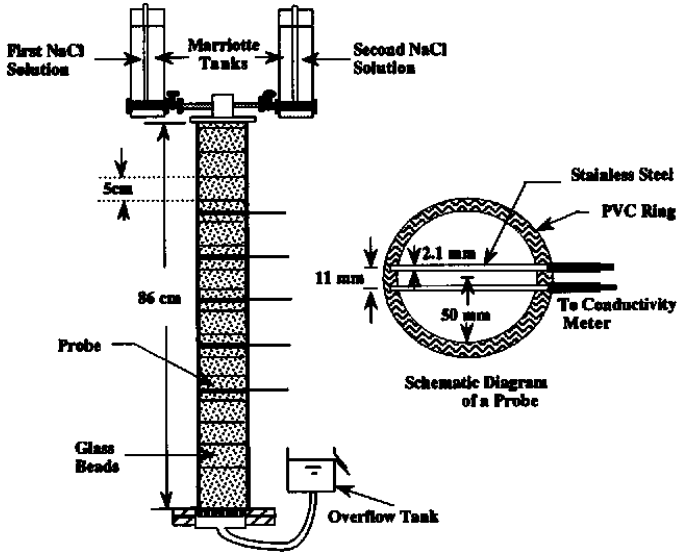

Fig. 2 Experimental set-up

tanks to supply the solution to the medium keeping the hydraulic head constant. The overflow tank was connected to the bottom of the medium to maintain the constant hydraulic gradient in a particular experiment. Glass beads were used as the porous materials.

\section{Experimental Procedure}

Glass beads were first washed with distilled water. Probes and PVC rings were stacked as shown in Fig. 2 and the rings were filled one by one with these glass beads. Packing of the beads was done carefully by tapping the column uniformly to get same average bulk density.

The $\mathrm{NaCl}$ solution of a given conductivity (ranging from 400 to $600 \mu \mathrm{S} / \mathrm{cm}$ ) was applied to the medium using a Marriotte tank. When the steady state flow condition was reached, another $\mathrm{NaCl}$ solution with higher electrical conductivity (ranging from 1600 to $2000 \mu / \mathrm{cm}$ ) was applied as a displacing solution at the same rate using another Marriotte tank. Electrical conductivities monitored by the probes installed in the column at $18.5,28.5,38.548 .5$ and $58.5 \mathrm{~cm}$ from the top medium surface were recorded in the computer.

All the experiments were conducted at a room temperature of $20 \pm 1^{\circ} \mathrm{C}$. Three sets of experiments under various hydraulic gradients to get

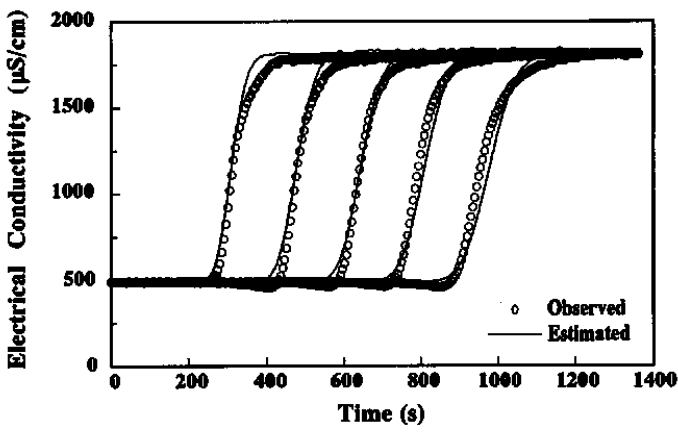

Fig. 3 Solute breakthrough curves at different locations inside the column

different flow rates were carried out, using three types of medium. Grain size distribution of each medium is sharp. We thus consider these medium as having uniform grain size of $0.25,0.50$ and $0.75 \mathrm{~mm}$ respectively.

\section{Analysis}

Measured electrical conductivities of beads and solution were converted into solution conductivities using probe calibration curves. Fig. 3 shows the change in electrical conductivities of the solution at different locations inside the porous medium with time. In Fig. 3, open circles denote the observed values of the electrical conductivities.

The mean pore water velocity and the dispersion coefficient were determined using the breakthrough curves shown in Fig. 3. The mean pore water velocity was determined by calculating the mean travel time taken by the solution to reach a certain location as:

$$
\bar{\nu}=\frac{L}{\delta t}
$$

where, $L$ is the distance $(\mathrm{cm})$ of a certain probe from the top of the medium, $\delta t$ is the time (s) taken by that probe to indicate the mean value of the electrical conductivities.

Dispersion coefficient was estimated by fitting the observed data to the analytical solution of one dimensional advection dispersion equation (ADE). One dimensional ADE for homogeneous 
moisture content condition inside the porous medium can be written as

$$
\frac{\partial C}{\partial t}=D \frac{\partial^{2} C}{\partial z^{2}}-\bar{\nu} \frac{\partial C}{\partial z}
$$

where, $t$ and $z$ are time (s) and the space coordinate $(\mathrm{cm})$ respectively.

The initial and boundary conditions of the experiments were as follows

$$
\begin{aligned}
& C=C_{0} ; \quad L>z>0, \quad t=0 \\
& -D \frac{\partial C}{\partial z}+\bar{\nu} C=\bar{\nu} C_{i} ; \quad z=0, \quad t>0 \\
& \frac{\partial C}{\partial z}=0 ; \quad z=L, \quad t>0
\end{aligned}
$$

Here, $C_{0}$ and $C_{i}$ are the concentrations of the original and the invading solutions respectively, $L$ is the column length $(\mathrm{cm})$.

Rose and Passioura (1971) stated that if Brenner number, i.e., $B=v L / D$, is large, the solution of the equation (15), with initial and boundary conditions as in equations (16a, b, c), can be given by,

$$
\begin{aligned}
C_{e}= & 1-\frac{1}{2}\left[\operatorname{erfc}\left\{\frac{\sqrt{B}}{2 \sqrt{T}}(1-T)\right\}\right. \\
& \left.+\exp (B) \operatorname{erfc}\left\{\frac{\sqrt{B}}{2 \sqrt{T}}(1+T)\right\}\right]
\end{aligned}
$$

at $z=L$. where $Z, T, B$ and $C_{e}$ are dimensionless variables defined as:

$$
\begin{aligned}
& Z=\frac{z}{L}, T=\frac{\bar{\nu} t}{L}, B=\frac{\bar{\nu}}{D} \\
& C_{e}=\frac{C-C_{i}}{C_{0}-C_{i}}
\end{aligned}
$$

This equation was applied to the observed BTCs to determine the dispersion coefficient. Fitting was obtained to minimize the sum of the square of the difference between observed and analytical solution of all probes. In Fig. 3 estimated BTCs are shown by solid lines. Good fittings were obtained.

\section{RESULTS AND DISCUSSION}

Dispersion coefficients obtained from a series of experiments under saturated conditions for each medium are plotted against pore water velocities in Fig. 4. Figure 4 shows that dispersion coefficient is increasing as a linear function [as given in equation (1)] with pore water velocity. Dispersivity, however, is larger in larger grain size medium than in the smaller size medium, i.e., $0.052,0.090$ and $0.134 \mathrm{~cm}$ respectively for $0.25,0.50$ and $0.75 \mathrm{~mm}$ grain size medium. These results are in agreement with the results reported in previous literature, e.g. Perkins and Johnston (1963), Bear and Verruijt (1987) etc. Bear and Verruijt (1987) also showed the range of particle Peclet number $\left(P_{e}=\bar{\nu} \bar{d} / D d\right.$; where $\bar{d}$ is the mean grain diameter of the porous medium and $D_{d}$ is the molecular diffusion coefficient) and $D / D_{d}$ in which $D-\bar{\nu}$ relationship is linear. Experimental data obtained from this study were plotted on their figure and found them fall in the linear zone.

The coefficient of variance $(\lambda)$ of pore water velocity is determined by equations $(4) \sim(10)$ and (13) using the suction-moisture content $(\psi$ $-\theta)$ and hydraulic conductivity-moisture content $(K-\theta)$ relationships. The $\lambda$ values thus obtained under saturated conditions for 0.25 , 0.50 and $0.75 \mathrm{~mm}$ beads sizes are $1.021,1.014$ and 0.974 respectively.

Mixing lengths, calculated using equation (12) for three uniform sized glass beads media, are plotted against average grain size of each medium in Fig. 5. Vertical lines in the plot show the range of mixing length for each group size. It shows that mixing lengths are almost constant for a given grain size medium in sa-

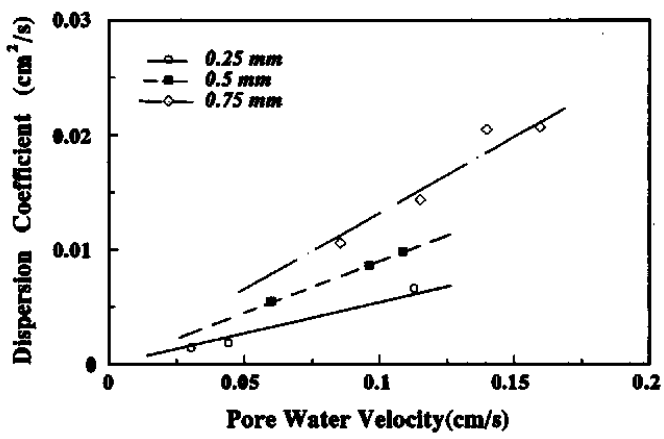

Fig. 4 Relation between dispersion coefficient and mean pore water velocity 


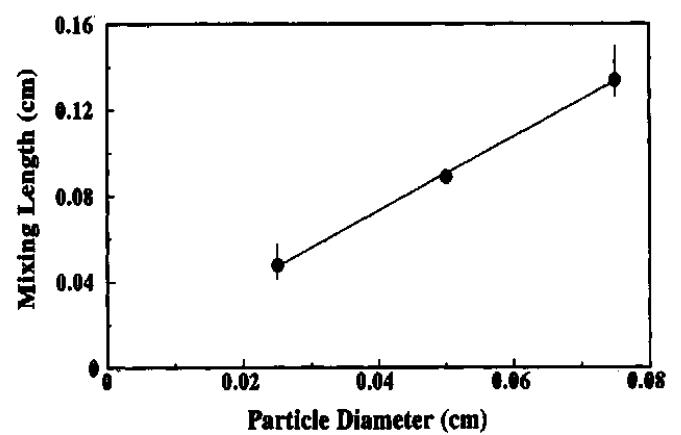

Fig. 5 Relation between mixing length and grain size

turated conditions. This is expected because all the pores are completely filled with water resulting similar flow pattern in each case under saturated conditions. The average mixing lengths are $0.048,0.089$ and $0.134 \mathrm{~cm}$ for the grain size of $0.25,0.50$ and $0.75 \mathrm{~mm}$ respectively.

These results show that mixing length of saturated condition is a function of grain size of the porous medium i.e., mixing length is increasing with increasing grain size of the medium. This is because solute has to travel a larger distance in one water path before it meets another one in the case of larger grain size medium. The "Mixing Length Number" defined by Matsubayashi $e t$ al. (1996) as the ratio of the mixing length to the particle diameter of the porous medium was found almost constant under saturated conditions. This constant assumed a value of about 1.8 , i.e.,

$$
l=1.8 \bar{d}
$$

The value of this coefficient, $l$, happens to be similar to the value of $\alpha$, i.e., 1.8 times the grain diameter reported in some previous literature (Fried and Combarnous, 1971; Bear, 1972), but this is simply because $\lambda$ values are almost unity for the materials used in this study. Because mixing length is a physically meaningful parameter, it is more logical to relate this parameter to mean grain size rather than relating dispersivity to grain size.

To discuss the mixing length of saturated

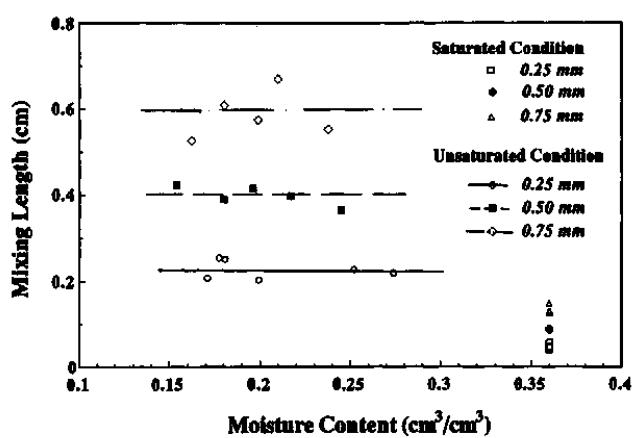

Fig. 6 Relation between mixing length and moisture content

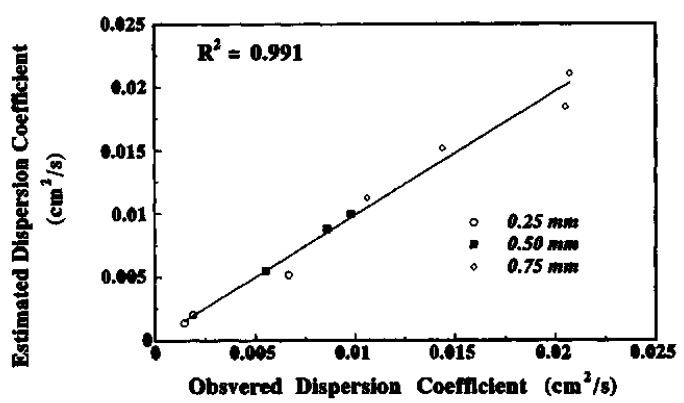

Fig. 7 Estimated dispersion coefficients vs observed dispersion coefficient

flow in comparison with unsaturated case, mixing lengths obtained under unsaturated (only in the lower range of moisture content) and saturated conditions are plotted against moisture contents in Fig. 6. If we look the mixing lengths for a particular grain size medium in saturated and unsaturated conditions, unsaturated mixing length is higher than saturated one. In the saturated condition adjacent water paths are close to each other and mixed after moving a small distance while in unsaturated case water particle has to travel a longer distance before getting mixed. This results in the larger mixing length and hence higher dispersion coefficient in unsaturated cases than in saturated cases.

The applicability of the model and parameters were checked by recalculating the dispersion coefficients using equation (12) with mix- 
ing length number equal to 1.8 . The estimated values are plotted in Fig. 7 against observed values. It shows that equation (12) is quite adequate to estimate the saturated dispersion coefficient of a porous medium having sharp grain size distribution.

\section{CONCLUSIONS}

The results of this study can be summarized as follows:

1. A relation for the dispersion coefficients is formulated using mixing length theory under saturated condition.

2. Dispersion coefficients are observed larger in larger grain size medium. This is due to the larger mixing length in larger grain size medium.

3 . Saturated mixing length has assumed a value about 1.8 times the grain diameter of the uniform grain size medium.

\section{REFERENCES}

Bear, J. (1972): Dynamics of fluids in porous media, American Elsevier, New York 746 pp.

Bear, J. and A. Verruijt (1987): Modeling groundwater flow and pollution, D. Reidel, Tokyo, $414 \mathrm{pp}$.

Freeze, R.A. and J.A. Cherry (1979): Groundwater, Prentice Hall, Englewood Cliffs, N.J., 604 pp.

Fried, J.J. and M.A. Combarnous (1971): Dispersion in porous media, Advances in Hydroscience, 7: 169-282.

Matsubayashi, U., L. P. Devkota and F. Takagi (1996): Characteristics of mixing length in dispersion through unsaturated glass beads media, Annual J. Hydraulic Engineering, JSCE, 40: 425-430.

Passioura, J.B. (1971): Hydrodynamic dispersion in aggregated media. Soil Sci., 111: 339334.

Perkins, T.K. and O.C Johnston (1963) A review of diffusion and dispersion in porous media. Soc. Pet. Eng. J. 70-84.

Rose, D. A. and J. B. Passioura (1971): The analysis of experiments on hydrodynamic dispersion. Soil Sci., 111: 252-257.

Scheidegger, A.E. (1961): General theory of dispersion in porous media. J. Geophys. Res, 66: $3273-3278$.

(Received: Apr. 18, 1996. Accepted: Aug. 12, 1996) 